\title{
An Investigation of the Scholarship and Bursary System for Postgraduate--Combined with the Establishment of MTI Scholarship Reform
}

\author{
Wang Ling, Liu Xiaochen, Wei Mengmeng \\ Department of Foreign Languages, School of Humanities, Tianjin University of Finance and Economics, Tianjin, China \\ Email address: \\ citylinda@tjufe.edu.cn (Wang Ling), liuxiaochen1936@163.com (Liu Xiaochen), Wei meng_meng@163.com (Wei Mengmeng)
}

\section{To cite this article:}

Wang Ling, Liu Xiaochen, Wei Mengmeng. An Investigation of the Scholarship and Bursary System for Postgraduate--Combined with the Establishment of MTI Scholarship Reform. Education Journal. Vol. 5, No. 5, 2016, pp. 97-101. doi: 10.11648/j.edu.20160505.13

Received: August 1, 2016; Accepted: August 15, 2016; Published: September 2, 2016

\begin{abstract}
Postgraduate education bears the burden to cultivate Chinese high-level talents. Postgraduates, a main force to establish an innovative country, play a critical role in scientific research. At present, as a breakthrough of postgraduate cultivation mechanism reform, scholarship and bursary system reform occupies an important position. This paper traces back history of bursary and scholarship theories, presents necessity and importance of reform. Authors explore some pertinent and feasible suggestions concerning bursary and scholarship system. Furthermore, combining with MTI (Master of Translation and Interpreting), authors render school-enterprise cooperation, in particular, an effective method to perform.
\end{abstract}

Keywords: Postgraduate, Bursary and Scholarship System Reform, MTI, School-Enterprise Cooperation

\section{Introduction}

\subsection{Background of Topic}

\subsubsection{Postgraduate Scholarship Reform}

In order to implement the spirit of $18^{\text {th }}$ CPC National Congress ( $18^{\text {th }}$ Communist Party of China National Congress) and carry out national education plan, Ministry of Education, NDRC and Ministry of Finance have drafted a series of documents to deepen all-round reform for postgraduate education in 2013. [1] These documents pointed out that we must perfect investment mechanism of focusing on government input, sharing cost reasonably for students and raising funds from company through multi-channel. Moreover, it is encouraging to establish a permanent and pluralistic supporting system and build a fair, just and open evaluation criteria. The documents also reinforced the function of national key projects to cultivation of high-level talents, stressing the importance of constructing sharing mechanism of high quality resources for major projects. The guiding ideology and basic principle of reform in education investment for postgraduate are clearly put forward as follows: [2] perfect education financial allocation system, improve supporting system and establish a sound tuition framework for postgraduates.

Announcement and implementation of comprehensive reform for postgraduate education which target on postgraduate education have great influence on the development of the country. It puts forward solutions to existing problems, which will be good for establishing an advanced educational system and improving the quality of postgraduate education. Above all, as a breakthrough of postgraduate cultivation mechanism reform, scholarships can stimulate postgraduates' study and research; can promote their ability to innovate; finally can improve the postgraduates' quality.

At present, Ministry of Finance and Ministry of Education have issued Temporal Methods for National Postgraduate Bursary Management and Temporal Methods for National Postgraduate Academic Scholarship, [3] which marked the preliminary improvement of postgraduate scholarship system. The system is made up of three main parts: State Grants, Academic Scholarships and National Scholarships. In addition to concrete policy, some assisting jobs, such as teaching assistant, research assistant and management assistant are offered. In addition, the student-loan together with a series of specific supporting policies is also provided for postgraduates. Chinese government has designed 
guidelines for dynamic management of postgraduate supporting system from the policy-oriented perspective; while the implementation and supervision of specific criteria are carried out by financial ministry and university administrative departments according to economic development level and price fluctuating situation. At last, the supporting standards and some adjustments are set up correspondingly.

Currently, various supporting system of postgraduate named "scholarship, assistant, subsidize, student-loan" has been established in our country and executed in seventeen national key universities since 2007. It aims to break the single mode of master scholarship system, meeting the basic living demands of postgraduate and encouraging students to devote themselves into scientific research. As a result, the quality of education is guaranteed actually. [4]

\subsubsection{The Necessity of Perfecting Scholarship System}

Postgraduate education is always an important way to cultivate high-level talents in China all the time. As national high-level talents and scientific research force, postgraduates take on great responsibility of research innovation. The quality of master education is pretty essential in the development and advancement of culture, science and technology. In recent years, with the development of educational cause and increasing number of postgraduates at college, postgraduate education plays an increasingly important role in social innovation. Furthermore, the expansion of university since 1999 has strengthened the scale of higher education, making the growth of postgraduates inevitable. The number of postgraduate has increased by one million in 2007. [5] However, expansion does not mean enhancement. Many schools, however, have just emphasized scale expansion, but neglected quality improvement. Thus, overall academic level declination triggered widespread concern. One undeniable reason is that the system is defective: it can reluctantly meet the basic living demand of postgraduate, which cannot make graduate fully concentrate on study and research. Nowadays, in terms of the quality of postgraduate education, there is still a big gap between our country and developed countries. The lack of creativity is far from meeting the requirements of cultivating innovative talents for our country.

Policy on supporting system in China is defective, compared with other developed countries, whose framework of aiding policy can be traced back to 1950 s. W. Schultz, Friedman and other famous economists, educators, higher education experts all did much investigation into education investment. W. Schultz once put forward the concept of human capital in his Human Capital Investment (1960), making it become integral part in the process of discussing education development decision and a convincing evidence for a country to provide financial aid with its students. Other masterpieces and classics were published in the following years by some other specialists like D. Bruce Johnstone, [6] a financial expert of comparative higher education in America, who propounded the theory of Cost-Recovery for higher education in his Sharing the Costs of Higher Education:
Student Financial Assistance in the United Kingdom, the Federal Republic of Germany, France, Sweden, and the United States. In addition, Woodhall generalized ten methods for education financial investment and made comprehensive summary of them in International Encyclopedia of Education.

\subsection{The Purpose and Significance of the Study}

In modern society, technology and science play a critical part of national soft power. Therefore, it is necessary to train a group of talents who have international perspective and innovative conscious, which both meet the requirements of enhancing soft power and national competence as well as chase the trend of times. Making full use of limited educational resources to boost creative talents training asks for bold reform on postgraduate education mechanism and detailed rules for implementing internal and sustainable cultivation system. Therefore, the quality of education will be increased dramatically under the guarantee of perfect institutional system. Scholarships can stimulate postgraduates' study and research; can promote their ability to innovate; finally can improve the whole postgraduates' quality.

Through investigation into scholarship and bursary system of postgraduate and reform of postgraduate education mechanism, combined with realities of MTI and employment market demand, the paper hopes to enrich research results to the development of higher education theoretically, deepening understanding to postgraduate training mode and promoting the improvement of supporting system. Under the direction of a sound and reasonable supporting system and combination the theory with MTI reality, cultivating of a group of professional, high-level, applicable-type talents can meet the demand of society. It is also meaningful to help postgraduates improve their living standard and meet the basic living demand.

\section{Review of Domestic Research Situation}

Relevant studies on scholarship and bursary system for postgraduate has just started in recent years at home. Zhang Xuanmin's Ideal and Choice: the international comparison of university student aid policy and Zhao Zhongjian's An international comparative study of Student loans in Colleges and Universities are representative works. Other scholars have published several papers in the core academic journals as well. Experts and scholars did systematic and complete research on scholarship and bursary system these years, and achievements in scientific research are shown in the following two aspects mainly.

\subsection{Theoretical Results of Scholarship and Bursary System for Postgraduate}

\subsubsection{The Theory of the Human Capital}

Qi Yeguo [7] once pointed out the reason that a nation should offer finance aid to students is that higher education is the means of national economic development. The theory holds that education contributes directly to the development of economy and investment in higher education will yield direct 
benefit, which has great influence on educational world.

\subsubsection{The Theory of Social Equity and Equal Educational Opportunity}

In Equal Opportunity of Higher Education, Changes of Policies on College Students' Financial Aid and New Challenges, Zhang Minxuan came up with the basic idea of government funding, which can be divided into two types: one is from the perspective of "social justice", benefiting every recipient; the other is from the perspective of "nurturing talents", benefiting the whole society. [8]

\subsubsection{Equity Theory \& Attribution Theory of Incentive Theory}

Resorting to empirical investigation method, Xu Mei, [9] a postgraduate of East China Normal University, selected some master students in two key universities where experiment reform of scholarship system had been carried out. She combined scholarship, "Three Assisting" work and tutor-subsidizing system to do an overall study. The application of these theories provides theoretical basis for this paper from management perspective.

\subsection{Suggestions and Envisions Towards Postgraduates}

Many scholars and experts have done much investigations into problems existing in the process of carrying out the supporting system of postgraduate named "scholarship, assistant, subsidize, student-loan". Meanwhile, they have proposed some constructive suggestions as well. For instance, in Postgraduate Education Charges and Related Principles Reforms, Li Wenli and Ding Xiaohao suggested that we should design a differential supporting system targeting on graduate assistance in postgraduate education and the supporting system should be divided into: "Three-Assisting" Grants, Scholarship and Student-loan. Lu Yi and Xiao Xiangyu advocated the construction of various supporting system focusing on onerous loan on the basis of analyzing existing problems and putting forward constructive opinions on postgraduate scholarship reform in Clear and Definite Idea on Establishment of Practical and New Type of Postgraduate Scholarship System. In addition to these scholars, reform plans were also launched successively in seventeen national key universities from 2006 to 2007. Officers in university will make overall arrangements of financial allocation for postgraduate training. For instance, partial research funds from their mentors and other funds raised through multi-channel to set up a scientific and new-type supporting system.

\section{Scholarship and Bursary System for MTI Postgraduate}

\subsection{Major Background}

Under the background of foreign trade mode transformation and cultivation of newly advantages in fierce international competition, great changes have taken place both in hierarchy of needs and demand structure for business talents. Especially in recent years, under the international environment of economic globalization, political multi-polarization, cultural diversification, science and technology integration and information network, professional translation talents play an increasingly important role in international market competition.

As a matter of fact, Chinese government has made efforts to cultivate a group of senior translators. The typical representative is the establishment of the major in Master of Translation and Interpretation in several universities. In 2007, The Plan for Setting up Specialties for MTI was passed in the $23^{\text {rd }}$ conference by Academic Degrees Committee of the State Council, marking the degree of MTI was established formally in China. [10]

\subsection{Existing Problems of MTI Scholarship and Bursary System}

\subsubsection{Defective System: Poor Coordination between Major and Supporting System}

The basic point on postgraduate cultivating reform is combining postgraduate cultivation with scientific research and mentor's scientific research task. Although it is generally accepted that instructors would pay a part of training costs for postgraduates from research funds in college. However, for MTI students, different from students in science and engineering major, lacking enough scientific research task, they have little opportunity to make full use of financial aid funds to conduct scientific research and obtain scholarship correspondingly in the end.

\subsubsection{Single Capital Source and Insufficient Volume of Investment}

At present, the fund of higher education is made up of government financial input, financing of universities, social donation and tutor-subsidizing. Among these investment sources, public financial investment is the most important capital source for postgraduate training; however, with the increasing number of students, government financial aid is obviously insufficient, making a lack of capital growth.

\subsubsection{Weak Connection Between College and Enterprise: Talents Can't Meet the Demand of Society}

From the perspective of social donation, although quite a few enterprises, graduates from the college and many celebrities have set up different kinds of scholarship in university, compared with other developed countries, the social donation is far from enough. According to statistics, if we split the whole Harvard funding from company and schoolmates' donation equally in 2007 , each student can get about 1.5 million dollar. This figure showed us a perfect and effective supporting system in the United States. In terms of assisting funds, we are still lagged behind those developed countries; Meanwhile, the single supporting mode lacks flexibility. Besides, the lack of mass participation hinders the development of supporting system in higher education to some extent. 


\subsection{School-Enterprise Cooperation -- Focus on the Establishment of MTI Scholarship System}

\subsubsection{Background of School-Enterprise Cooperation}

As for MTI students, the so-called school-enterprise cooperation means cultivating applicable-type talents who can meet the development of market economy through integration and sharing talents, technology and resources between school and enterprise. School-enterprise cooperation is a win-win strategy, from which entrepreneurs and students, donor and recipients can benefit spiritually and materially.

Through school-enterprise cooperation, company can obtain a group of high-level talents, which lays the foundation for storing talents resources. Besides, it is also beneficial to facilitate enterprise cultural power, which will speed up the establishment of enterprise culture. As for universities, they can get technology support and market information, which will promote the fulfillment of teaching task and achieve scientific research target. Through combination of knowledge with techniques, students, therefore, can get lots of opportunities to take part in social practice, which will not only be good for looking for jobs in the future, but also reinforcing the function of scholarship to encourage them to finish their scientific research task. Enforcing the school-enterprise cooperation strategy will be beneficial for realizing the integration of resources, making the cultivation of talents meet the demand of society, promoting transformation of talents training mode: from knowledgeable-type to applicable-type.

\subsubsection{Ways of School-Enterprise Cooperation}

i. "Order Cultivation" Pattern - Set up Long-term Cooperation Mechanism.

The so-called order-cultivation pattern means that university administrators can sign up a contract with a firm or other social institutions and promise them to cultivate MTI postgraduates according to the contract. This training mode not only provides company with proper and satisfying talents, but saves time and cost of training freshmen to adjust their new positions. By establishing a perfect scholarship and bursary system for postgraduate, entrepreneurs offer MTI students job opportunities and salaries to inspire qualified ones. For MTI students, they have good opportunity to put theory into practice; meanwhile, they can get income or scholarship. Similar successful example like this is BFSU Translation Class: Translators were trained for Olympic Games in 2008 by Beijing Foreign Study University.

ii. Program Cooperation--Building up University-Industry Cooperation Platform.

It refers to school and enterprise can cooperate with each other concerning a long-term or a short- term program. Companies, scientific research institution and university teachers may sign up a contract in order to let their cooperation go smoothly. Their cooperation field contains translation teaching, scientific research, development of software and testament. It is of vital importance to promote the sharing of resources, take advantage of each other strength, deepen cooperation between school and enterprise, and achieve actual combination. Once MTI students put themselves into the program, they will use their knowledge to make contribution to the scientific research. In addition, they would develop rigorous attitude, increase academic level and get funding aid at the same time. For example, Translation and Language Service series published by Peking University. The authors include experts and postgraduates from colleges and universities, members of Translators' Association, representatives from Language Service Enterprise and scholars from relative fields. Some books, as scientific research results, have been published already in recent years. [11]

iii. Scholarship and Bursary System--Incentive Mode Promoting Development

Scholarship and bursary imply that companies offer funding aid to school or relative institutions to set up scholarship for MTI postgraduate. The money is used to help potential talents complete their studies and encourage excellent MTI students. Under these circumstances, enterprise can participate in MTI talents discovery, cultivation and reservation, promoting the spread of advanced translation theory and technology. On the environment of establishing national innovative system, postgraduate student serve as the main force of science and technology innovation, bringing continuous vigor and energy into scientific innovation. Entrepreneurs, under the full charge system, setting up special fund and combining students' research result with the amount of bonus will inspire students' ability to innovate and increase the quality of higher education.

\section{Summary}

Under the background of postgraduate scholarship reform, the paper aims to trace the evolution history of postgraduate scholarship theory and practice on the basis of introduction and analysis to new supporting system. By analyzing the existing problems in postgraduate scholarship system, the authors find that reform of supporting system must be on the way and makes some pertinent and feasible suggestions to cultivate MTI students to meet the demand of society and reform. School-enterprise cooperation, in particular, is an effective method to improve the defective system at present. It ensures sustainable capital source and enriches research results to the establishment postgraduate scholarship system theoretically. Furthermore, it strengthens the connection between students and company, namely, it strengthens the connection between market demand and employees actually. Postgraduates, as a group of high-level employees in the society can apply their knowledge to practice. Moreover, putting theory into practice is to fulfill their self-value and let them make contributions to society at the same time. However, it is a remarkable fact that current study shows that the school-enterprise cooperation is the inevitable trend of MTI talents cultivation. How to make students' research results satisfied by university and enterprise and achieve maximum of profit is worth further investigation. Government should draft reasonable and timely supportive policy; meanwhile, 
university, enterprise and students should make joint efforts to promote the solution of the problem finally.

Anyway, there still exist some shortcomings in this article. For example, due to the shortage of related material and relevant specialized terms, it is difficult for us to make it absolutely right in the diction. Besides, by employing the method of literature review and contrastive study, the author has done much investigation into the theory and practice of postgraduate reform. However, there still exist some incomplete research of all the theories no matter from abroad or at home. Last but not least, the reform on MTI postgraduates needs to be deepened comprehensively in the near future and it is worthwhile to expect a all-round reform of postgraduate education.

\section{References}

[1] Cai Hui, Zhang Chengzhi. School-Enterprise Cooperation concerning MTI [J]. Chinese Translators Journal No. 1, 2013.

[2] Chen Chao. A Study on Federal Government Graduate Student Tuition and Policy [J]. China Higher Education Research, 2005 (8).

[3] Gong Jingbo. Probe into the Establishing of Newly Postgraduate Supporting System [D]. Central South University, 2007.
[4] Johnstone, D. B., \& Marcucci, P. (2010). Financing higher education in international perspective: Who pays? Who should pay? [M] Baltimore, MD: The Johns Hopkins University Press.

[5] Johnstone, D. B, d'Ambrosio, M., \& Yakoboski, P. (Eds.), (2010). Higher education in a global society. New York, NY/Northampton [M], MA: Edward Elgar Publishing.

[6] Li Wenli, Di Xiaohao. Consideration about Graduate Tuition and Policy Reform [J]. Academic Degree \& Graduate Education, 2003 (12).

[7] Lu Yi Affirm Policy and Create Newly-type Graduate Scholarship and Bursary System [J]. Academic Degree \& Graduate Education, 2006 (10).

[8] Qi Yeguo, Xin Haide. Theoretical Basis of Charges in Colleges and Universities and Student Financial Aid [J]. Jiangsu Higher Education, 1998.

[9] Xu Mei. Research on Merit and Bursary System for Graduate Student Under the Reform of Graduate Student Education Mechanism [D], East China Normal University, 2008.

[10] Yang Xiaoying, Yin Zheng, He Qixun, Cao Jie. Present Situation and Reform of Postgraduate Scholarship and Bursary System [J]. Capital Medicine University Journal, 2011.

[11] Zhang Baiying, Yu Dewei. Research on MTI Education Mode: Based on Market's Need [J]. Education Science Vol 31, No. 3, 2015 (6). 